\title{
A Rare Case of Nasal-Orbital-Cranial Aneurysmal Bone Cyst
}

\author{
MUBASHIR MALIK, USAMA MUHAMMAD KATHIA, ZOHA FAYYAZ \\ RIZWAN MASOOD BUTT \\ Department of Neurosurgery, Punjab Institute of Neuroscience (PINS), PGMI, Lahore - Pakistan \\ DOI 10.36552/pjns.v24i2.425
}

\begin{abstract}
Aneurysmal bone cysts of skull are rare and involvement of sphenoid bone is even less. We are presenting a rare case of aneurysmal bone cyst involving ethmoidal sinuses, maxillary sinuses, frontal sinuses, sphenoidal sinuses, basisphenoid bone, and left orbit with intracranial extension in a 9 year old female. The diagnosis was confirmed using CT, MRI-brain, CT-angio brain imaging. The finding of nasal-orbital-cranial aneurysmal bone cyst was confirmed on Histopathology. Two staged surgical excision planned and done, i.e. trans-cranial and trans-nasal excision.
\end{abstract}

Keywords: Aneurysmal bone cyst, cranial, nasal.

Abbreviations: ABC: Aneurysmal Bone Cyst. ENT: Ear Nose and Throat. CT: Computed Tomography. MRI: Magnetic Resonance Imaging.

\section{INTRODUCTION}

Aneurysmal bone cyst $(\mathrm{ABC})$ can be defined as a benign lesion of the bone and it rarely involves the skull base. $\mathrm{ABC}$ was originally identified as a unique pathology by Jaffe and Lichtenstein et al. in $1942{ }^{1}$ Previously, such an anomaly was diagnosed as ossifying sub-periosteal hematomas, sub periosteal giant cell tumors, aneurysmal giant cell tumors, benign bone aneurysms and atypical giant cell tumors. ${ }^{3}$ Up to $50 \%$ of Aneurysmal bone cyst cases are located at the end of long bones, $25 \%$ involve the vertebrae and only $3 \%$ are located in the cranium. ${ }^{2}$ It can either be a primary $\mathrm{ABC}$ or can be of secondary origin based upon bone growth elsewhere. The most common causes of secondary $\mathrm{ABC}$ are Chondroblastoma and Giant cell tumors. ${ }^{4}$

ABC usually affect the young with $90 \%$ of the patients present at less than 20 years of age. It is rapid in growth. In cranial lesion the signs and symptoms depend on the location of ABC inside the skull. ${ }^{3}$

\section{Case}

A 9 year old female presented with the history of epistaxis followed by the proptosis of the left eye in the ENT outpatient department. She also had complained about something coming out of her nose for which she was admitted in ENT department. A biopsy of the lesion was taken from trans-nasal route by ENT. On histopathology, it came out to be an Aneurysmal Bone Cyst (ABC). She has no any other disease and family history was also not significant. She was referred to Neurosurgery for further management.

She presented in the Neurosurgery outpatient department on $13^{\text {th }}$ November 2019 and was admitted on the same day. On examination, she had significant left sided proptosis with ipsilateral papilledema. Her vision was intact bilaterally but she had bilateral anosmia. She had hypoesthesia of the left side in the dermatomes of $\mathrm{V}_{1}, \mathrm{~V}_{2}$ and $\mathrm{V}_{3}$ nerves.

\section{Investigations}

Her MRI brain and Orbital plain was done on $19^{\text {th }}$ October 2019 which showed a well-defined, multiloculated expansile lesion arising from hard palate. Its size was $9.05 \times 5.5 \mathrm{~cm}$ and it showed multiple fluid-fluid levels, which were indicative of a hemorrhagic component (Figure 1). The mass was 
extending into the left infratemporal fossa, and caused erosion of left lamina papyracea with left infraorbital extension. Posteriorly, it was extended up to Basisphenoid.

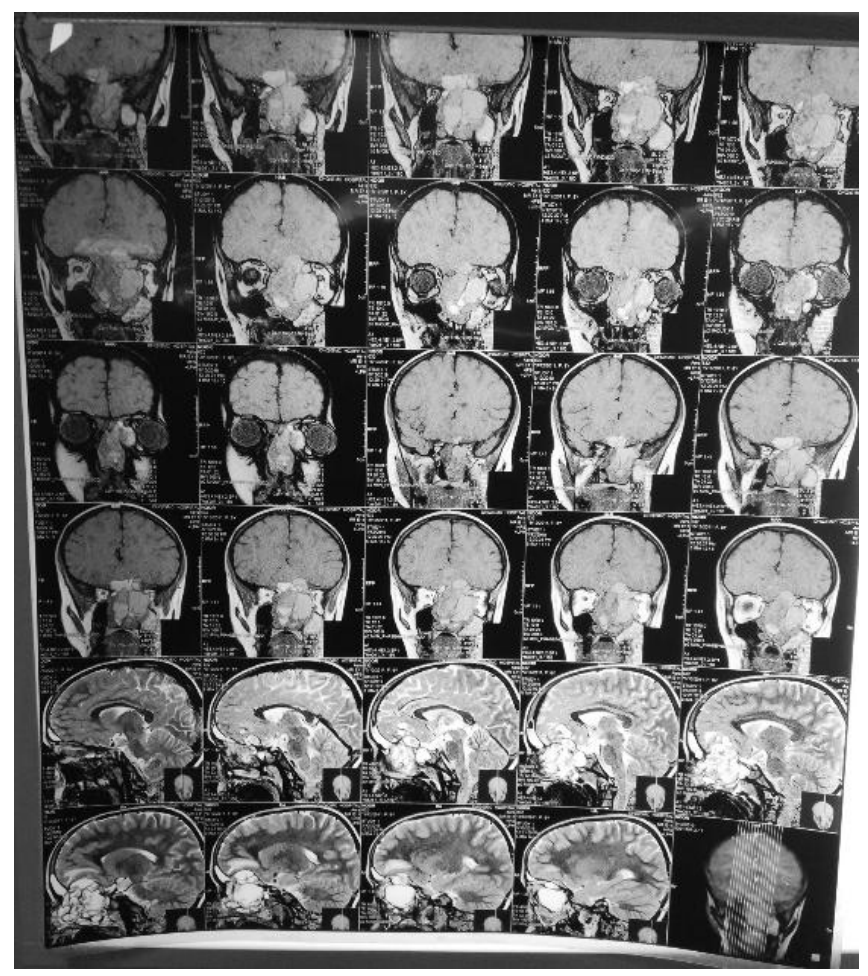

Fig. 1: $M R I T 1 W$ and $T 2 W$ in Sagittal and Coronal Sections.

A CT FESS protocol was done on $5^{\text {th }}$ December 2019 and showed a large ill-defined heterogeneous mass involving ethmoid sinuses, nasal cavity and bilateral sphenoid sinuses (Figure 2). This mass was shown to be causing bone remodeling in the patient.

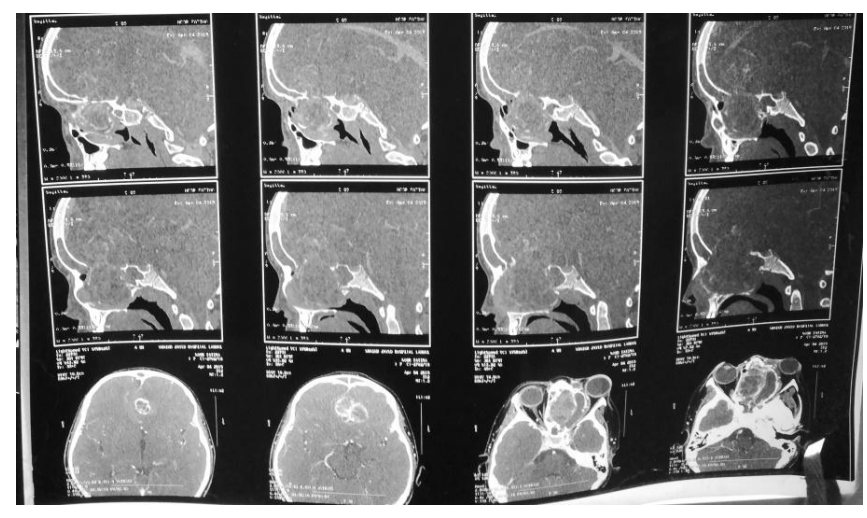

Fig. 2: CT FESS Protocol.

\section{Treatment}

Surgical excision of the aneurysmal bone cyst was planned. Initially two stage procedure was planned for the removal of this $\mathrm{ABC}$ in which trans-cranial excision and trans-nasal endoscopic excision were to be done.

\section{Stage 1 Operation}

But the plan was revised and in first surgery the skull based $\mathrm{ABC}$ was excised trans-cranially via sub-frontal approach. Subtotal resection done. Peri-operatively there was necrotic, avascular, cystic, hard tumor involving the sphenoid, ethmoid, maxillary and frontal sinuses and extending into the left orbit.

\section{Stage 1 Operation}

The second stage operation was done 1 month after the $1^{\text {st }}$ surgery, via same transcranial sub-frontal approach. Left medial orbitectomy was also done. Solid to cystic lesion of bone was noted perioperatively. Gross total excision was performed outcome.

The patient remained in the ward for 10 days after the second procedure. CT scan brain with bony reconstruction was done to see the extent of resection, which was satisfying. The patient was discharged after skin stitch removal and is currently on follow-up.

\section{Future Plan}

The next plan was to involve the maxillofacial and plastic surgeons for better cosmetic outcome of the patient.

\section{DISCUSSION}

Aneurysmal bone cysts in the skull are very rarely encountered. But when it does, it poses its unique management challenges. It is important to know the extent of the lesion because a skull is a compact closed cavity enclosing essential structures. And although primary $\mathrm{ABC}$ is not itself lethal, it can cause a wide variety of symptoms in a patient to cause significant morbidity.

The extent of the ABC is usually determined by certain radiological investigations. MRI of the brain is commonly used for this purpose. It can help us appreciate the origin as well as the extent of the tumor. CT brain plain is also used for this purpose. We used CT FESS protocol, which is a focused scan of the 
paranasal sinuses in coronal plane only. It shows only seven slices. It is shown to help with the determination of paranasal sinus disease and it also reduces patient's exposure to radiation and cost. ${ }^{5} \mathrm{We}$ also performed a CT-angio on this patient to know the vascularity of the lesion. The $\mathrm{ABC}$ of the skull is known to be a very vascular tumor. So it's important to know the vascular status of the tumor.

Once the Anatomy of the ABC is determined, the next step is the treatment plan. It's important to understand the rationale of surgery in primary $A B C$ like our case; it should be to relieve the symptoms that the patient is suffering from due to it. The treatment is total excision of the mass. But as much of the mass should be excised as is safely possible. ${ }^{6}$ The other options for treatment may include sclerotherapy or cryotherapy, which can be used in adjuvant to surgery as well. ${ }^{7}$ We planned a safe resection of the ABC as much as to relieve the symptoms the patient was suffering from including proptosis. Our initial plan of two stage operation in which one procedure was to be done Trans-cranially and the other Trans-nasally was not followed. The reason was that the tumor was too large to be excised trans-nasally and hence both procedures were performed Trans-cranially. The patient showed good results post-operatively and her symptoms gradually resolved.

Cosmetic outlook is also a very important aspect of such surgeries, especially in patients of younger age group and female gender. Hence this aspect of patient care should not be ignored. This emphasizes the role of multi-disciplinary approach in such patients with inputs from Plastic and Maxillofacial Surgeons.

\section{CONCLUSION}

Aneurysmal Bone cyst of nasal bone with intra-orbital and intra-cranial extensions is extremely rare pathology. CT and MRI are the imaging modalities used for evaluation of $\mathrm{ABC}$, aiding in diagnosis and helpful in treatment planning. The treatment is total surgical excision with goal to relieve symptoms of the patient. Cosmetic acceptability should not be over looked.

\section{REFERENCES}

1. Jaffe HL, Lichtenstein L: Solitary unicameral bone cyst with emphasis on roentgen picture, pathologic appearance and the pathogenesis. Arch Surgery, 1942; 44: 1004-1025.

2. Dubois J, Chigot V, Grimard G, Isler M, Garel L: Sclerotherapy in aneurysmal bone cysts in children: A rewiev of 17 cases. Pediatr Radiol. 2003; 33: 365-372.

3. Ameli NO, Abbassioun K, Azod A, Saleh H. Aneurysmal bone cyst of the skull. Canadian journal of neurological sciences, 1984; 11 (4): 466-71.

4. Gutierrez LB, Link TM, Horvai AE, Joseph GB, O'Donnell RJ, Motamedi D. Secondary aneurysmal bone cysts and associated primary lesions: imaging features of 49 cases. Clinical Imaging, 2020.

5. El-Hakim H, McClymont L. Target oriented computed tomography-scanning of the paranasal sinuses. Clinical otolaryngology and allied sciences, 1998; 23 (1): 77-81.

6. Hermann AL, Polivka M, Loit MP, Guichard JP, Bousson V. Aneurysmal bone cyst of the frontal boneA radiologic-pathologic correlation. Journal of radiology case reports, 2018; 12 (7): 16.

7. Gan YC, Hockley AD. Aneurysmal bone cysts of the cranium in children: Report of three cases and brief review of the literature. Journal of Neurosurgery: Pediatrics, 2007; 106 (5): 401-6.

\section{Additional Information}

Disclosures: Authors report no conflict of interest.

Ethical Review Board Approval: The study was conformed to the ethical review board requirements.

Human Subjects: Consent was obtained by all patients/participants in this study.

Conflicts of Interest:

In compliance with the ICMJE uniform disclosure form, all authors declare the following:

Financial Relationships: All authors have declared that they have no financial relationships at present or within the previous three years with any organizations that might have an interest in the submitted work.

Other Relationships: All authors have declared that there are no other relationships or activities that could appear to have influenced the submitted work. 
Address for Correspondence:

Mubashir Malik

Punjab Institute of Neuroscience

Lahore - Pakistan

Email: drmubashirmalik151@gmail.com

\section{AUTHORSHIP AND CONTRIBUTION DECLARATION}

\begin{tabular}{|l|l|l|}
\hline Sr.\# & Author's Full Name & Intellectual/Contribution to Paper in Terms of: \\
\hline 1. & Mubashir Malik & 1. Main investigator/data collection. \\
\cline { 1 - 2 } 2. & Usama Muhammad Kathia & 2. Data analysis and report writing. \\
\cline { 1 - 2 } 3. & Zoha Fayyaz & 3. Literature review. \\
\cline { 1 - 2 } 4. & Rizwan Masood Butt & 4. Analysis of data and quality insurance. \\
\hline
\end{tabular}

Date of Submission: 19-4-2020

Date of Revision: 10-05-2020

Date of Online Publishing: 30-06-2020

Date of Print: 30-07-2020 